\title{
High Power Efficiency Buck Converter Design for Standalone Wind Generation System
}

\author{
Yigeng Huangfu, Ruiqing Ma, Bo Liang, and Yuren Li \\ Northwestern Polytechnical University, Xian 710072, China \\ Correspondence should be addressed to Yigeng Huangfu; yigeng@nwpu.edu.cn
}

Received 20 November 2014; Accepted 30 December 2014

Academic Editor: Weiren Zhu

Copyright (c) 2015 Yigeng Huangfu et al. This is an open access article distributed under the Creative Commons Attribution License, which permits unrestricted use, distribution, and reproduction in any medium, provided the original work is properly cited.

\begin{abstract}
In wind generation system, the power converter efficiency is one of the key factors for the performance of the system. In those systems, DC/DC Buck converter is widely used for high power system. Considering the converter's cost and efficiency, this paper mainly focuses on the design of an improved topology Buck converter adopted for high power standalone wind generation system. The designed converter uses multi-MOSFETs in parallel instead of the IGBTs, in order to increase the conductive current as well as the converter switch frequency. From the experimental tests results, the maximum efficiency of the designed $2 \mathrm{~kW}$ Buck converter is up to $96 \%$ based on maximum power point tracking (MPPT) method.
\end{abstract}

\section{Introduction}

Conventional energy resources may run out in the following few decades, especially from fossil origins, which could lead to the energy shortage in the world. The energy consumption is increased dramatically in recent years. The renewable energy sources, such as solar, wind, or ocean wave energy, are considered to be the future energy solutions. Thanks to the extensive research in renewable energy field, those energies can be exploited more and more easily and properly [1-3]. Nevertheless, being neglected for a long time, power extraction techniques of these resources require more researches and developments aiming to reduce the manufacturing costs and to improve the energy efficiency [4].

Among the renewable resources, the wind energy is gaining greater visibility during the last several years as a convenient and promising energy source in the future [5]. The application of wind energy is divided into two aspects. One is a standalone wind power station with the battery as energy storage component, and the other is connect-to-grid wind turbine. In many applications, such as small villages or islands power station, the off-grid wind power generation system provides an excellent energy solution. However, they are unstable energy sources due to their primary source in nature. Thus, an energy storage component is usually added to form a hybrid energy system. In such a system, a suitable power converter plays an important role during energy conversion and management. Generally, in order to improve the system efficiency these converters should be adaptive for wide wind speed range.

In a wind generation system, two types of converter can be usually found: a primary AC/DC converter connected directly to the wind turbine generator and a secondary DC/DC converter connected to the load. As known, the nonisolated DC/DC Buck converter is usually used in small or low power system, and the soft-switching technology is widely used to improve the efficiency. In [6], two high efficiency voltage regulators based on Buck converter with soft-switching for CPU power have been proposed, with a relatively small system power output. In a high power system, IGBTs based Buck converters with soft-switching technology are commonly used. In [7], the design of a single phase (synchronous rectification), interleaved synchronous mode bidirectional converter is given. Due to the cost limitation of the system, the soft-switching Buck converter with MOSFET rather than IGBT is used. In [8], a high efficiency zero-current switching (ZCS) Buck converter has been also presented.

The main focus of this paper is to present a low cost, high efficiency DC/DC converter design in a wind generation system. Considering the cost, efficiency, power level, and 


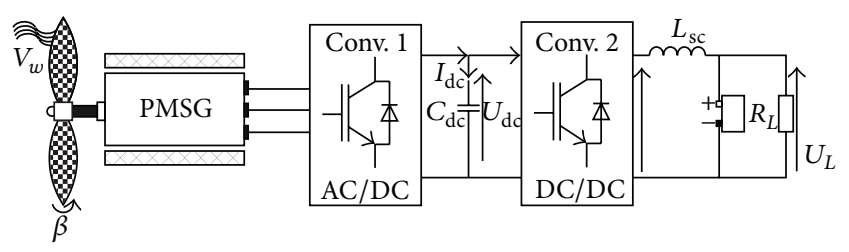

FIGURE 1: Standalone wind power generation system.

the characteristic of such a wind system, the technology of paralleled multi-MOSFETs devices is used and an optimized Buck converter topology is presented with the experimental validation.

\section{System Structure}

Generally, six parts can be distinguished in a standalone wind power generation system. They are wind turbine, permanent magnet synchronous generator (PMSG), AC/DC rectifier, $\mathrm{DC} / \mathrm{DC}$ converter, storage battery, and load, respectively. The structure is presented in Figure 1.

The wind energy in nature drives the turbine to whirl. The PMSG produces the AC electrical energy, whose amplitude and frequency are variable because of the random wind speed in the nature. Through the $\mathrm{AC} / \mathrm{DC}$ rectifier, the $\mathrm{DC}$ electrical energy with alterable amplitude is obtained. Compared with conventional Buck converter, the wide input voltage range is a novel challenge for the converter design. For system performance, the maximum power point tracking (MPPT) technology control method is used $[9,10]$ to ensure a stable DC output for the storage battery and load.

2.1. Wind Turbine Characteristic. As well known, the rated power of the wind turbine depends on the length of blade, air density, power coefficient, and wind speed. Moreover, mechanical elevation and transmission affect the rated power. The relation can be expressed by [11]

$$
P_{\text {turb }}=0.5 \rho C_{p}(\lambda, \beta) \pi r^{2} v^{3} \eta
$$

where $\rho$ is the air density, $r$ is the blade length, $v$ is the wind speed, $\eta$ is the transmission efficiency, and $C_{p}$ is the power coefficient depending on the pitch angle of rotor blades $\beta$ and the tip speed ratio $\lambda$. When the pitch angle is constant, $C_{p}$ depends only on tip speed ratio $\lambda$, as shown in Figure 2.

The tip speed ratio is defined by

$$
\lambda=\frac{r \omega}{v}
$$

where $\omega$ is the angular speed of wind turbine.

When the turbine operates at its optimal point, the rated wind speed $v$ can be thus expressed as a function of the wind turbine speed:

$$
v=\frac{r \omega}{\lambda_{\mathrm{opt}}} .
$$

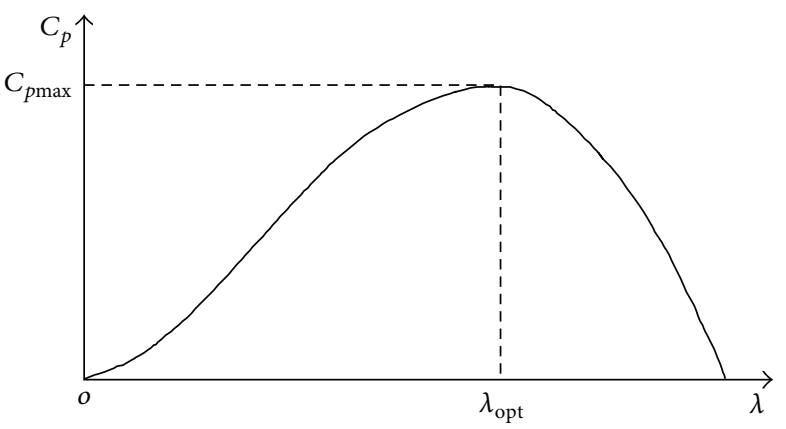

FIGURE 2: Blade characteristic: $C_{p}$ versus $\lambda$.

From (1) and (3), the output power from wind turbine can be expressed by

$$
P_{\mathrm{MPPT}}=0.5 \rho C_{p \max } \pi r^{2}\left(\frac{r \omega}{\lambda_{\mathrm{opt}}}\right)^{3} \eta=K_{\mathrm{opt}} \omega^{3}
$$

with

$$
K_{\mathrm{opt}}=\frac{\rho \pi r^{5} C_{p \max }}{\lambda_{\mathrm{opt}}^{3}} .
$$

The turbine torque is defined as the ratio of the mechanical power to the rotational turbine speed:

$$
T_{\mathrm{opt}}=\frac{P_{\mathrm{MPPT}}}{\omega}=K_{\mathrm{opt}} \omega^{2} .
$$

Equations (4) and (6) provide the relation between the maximal mechanical power and the turbine speed, as well as the relation between the maximal torque and the turbine speed. When the wind generation system works at its maximum power point under a given wind speed, the wind speed and tip speed ratio can be calculated by (3).

With different wind speeds, the output power and torque of turbine and their maximum point are shown in Figure 3. Figure 3(a) presents the mechanical output power versus the wind speed. Figure 3 (b) presents the mechanical output torque versus the wind speed.

2.2. Permanent Magnet Synchronous Generator (PMSG) Characteristic. The permanent magnet machines are used more and more in the variable speed drives. The PMSG used in the presented system is a generator with radial magnetization [12]. Thus, the synchronous rotating coordinate $d-q$ axis has the same speed with the rotor magnetic poles. The stator voltage equations of PMSG can be expressed by

$$
\begin{aligned}
& u_{d}=R_{s} i_{d}+L_{d} \frac{d i_{d}}{d t}+\frac{d \psi_{f}}{d t}-\omega_{e} L_{q} i_{q}, \\
& u_{q}=R_{s} i_{q}+L_{q} \frac{d i_{q}}{d t}+\omega_{e}\left(L_{d} i_{d}+\psi_{f}\right),
\end{aligned}
$$

where $u_{d}$ and $u_{q}$ are $d-q$ axis voltages, respectively; $i_{d}$ and $i_{q}$ are $d-q$ axis currents, respectively; $L_{d}$ and $L_{q}$ are $d-q$ axis selfinductions, respectively; $\omega_{e}$ is the electricity angular velocity 


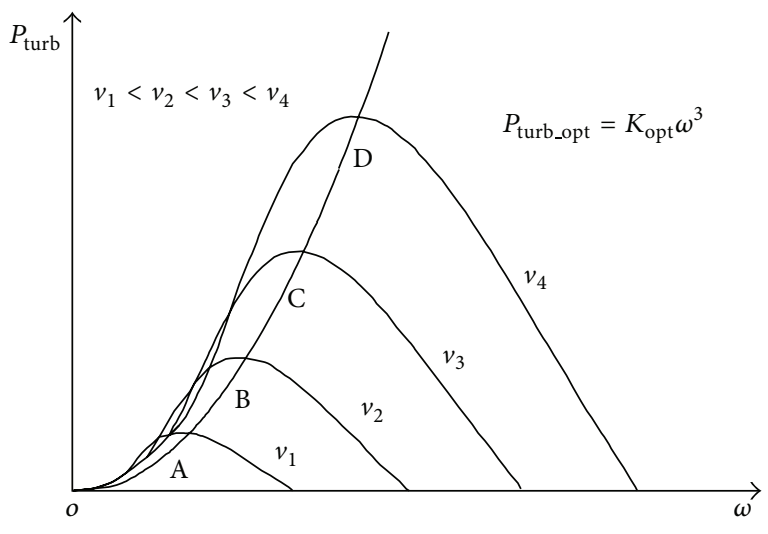

(a)

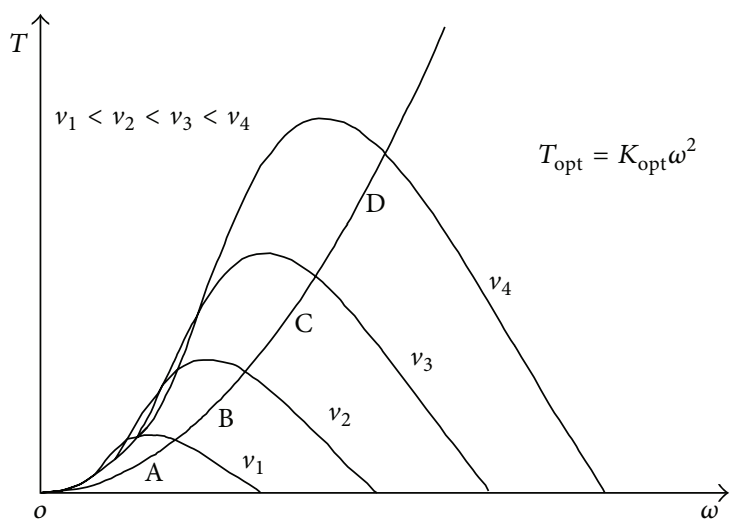

(b)

FIGURE 3: Output characteristic of wind turbine.

with $\omega_{e}=p \omega ; p$ is the pairs of poles; and $\psi_{f}$ is the flux linkage of permanent magnet.

The equation of electromagnetic torque can be calculated as

$$
T_{\mathrm{em}}=1.5 p\left[\psi_{f} i_{q}+\left(L_{d}-L_{q}\right) i_{q} i_{d}\right] .
$$

In the case of a nonsalient pole machine, $L_{d}=L_{q}$. The equation above can be therefore rewritten by

$$
T_{\mathrm{em}}=1.5 p \psi_{f} i_{q}
$$

Thus the electromagnetic torque depends only on the $q$ axis component current. The flux is constant, and the torque is proportional to the current $i_{q}$.

2.3. Discussion on MPPT Control Method. The common maximum power point tracking (MPPT) methods such as optimum tip speed ratio, power curve control, and climbing mountain can be found in the literature $[13,14]$.

With the method of optimum tip speed ratio, the wind speed $v$ and turbine speed $\omega$ have to be measured at first. The result of the ratio $\lambda=r \omega / v$ is then compared with the optimum ration of tip speed $\lambda_{\text {opt }}$ shown in Figure 2 . The error is sent to the controller to adjust the duty cycle of PWM for power converter. This method has a clear physical conception and a simple theory. However, it is necessary to measure the wind speed and turbine speed precisely. The control block diagram of this method is shown in Figure 4.

The wind speed is difficult to detect accurately due to the randomness and intermission of wind in nature. Furthermore, the use of wind speed sensor will increase the cost of the system. In addition, the optimum tip speed ratio is defined by turbine generator manufacturer, which is not easy to obtain. As a consequence, this method is rarely used in actual applications.

If the power curve control method is used, only turbine angular speed needs to be measured. According to (4), the power curve can be obtained at certain wind speed. Thus, the maximum power point can be obtained. At this time, the error between the actual output power and the given reference power is used as the input of controller. The control block diagram of power curve is shown in Figure 5.

The disadvantage of this method is that the output power of generator and the optimum power curve should be known. The use of the turbine torque sensor also increases the cost of the system. In addition, the maximum power curve is usually obtained by offline test. The variation of parameters during system operation will affect the efficiency of the maximum power tracking method in the system.

The climbing mountain method overcomes the disadvantages of the two methods mentioned above. This method uses an empirical search algorithm for control purpose. Thus the measurements of wind speed and the power curve of the generator are not needed. The wind turbine speed can be regulated by changing the generator output power. The search algorithm adjusts continuously the PWM duty cycle until system operates at its maximum power point. The control block diagram of climbing mountain is shown in Figure 6.

During the PWM regulation, if the duty cycle step change is too big, the oscillation will take place. In this case, the regulated maximum power point by this method is far away from the real optimal value. Thus the performance of system is decreased. If the PWM duty cycle step change is too small, the tracking method cannot converge to optimal point rapidly. In this paper, a variable duty cycle change step is used for climbing mountain method. The control algorithm flow chart is shown in Figure 7.

Because the energy storage adopts four VRLA batteries in parallel, the terminal voltage is almost constant. Actually, maximization of output current achieves the highest power control. After program initialization, the initial output current $I$ is detected. The $I_{\max }$ is the maximum current under the same wind speed, and the $I_{1}$ is the output current at next sample time. When the error between $I_{1}$ and $I_{\max }$ is larger than preset $\alpha$, the duty cycle should be reinstalled. Otherwise, the duty cycle remains unchanged. If the output current $I_{1}$ is much lower than maximum current $I_{\max }$ and $I_{1}-I_{\max }<$ $-\alpha$, the duty cycle should make adjustment with disturbance duty. Then, the output current is measured again, denoted by $I_{2}$. Similarly, the output current $I_{2}$ also compares with $I_{\max }$. 


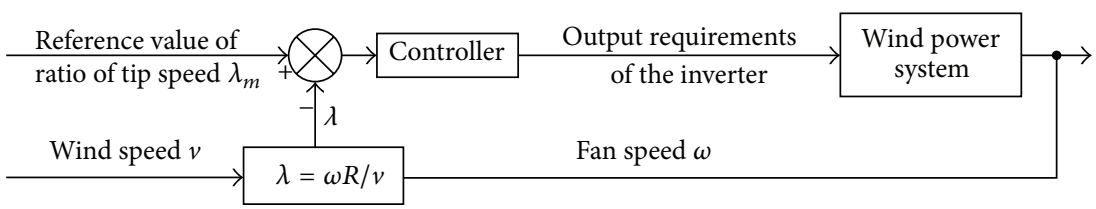

FiguRE 4: Block diagram of optimum tip speed ratio.

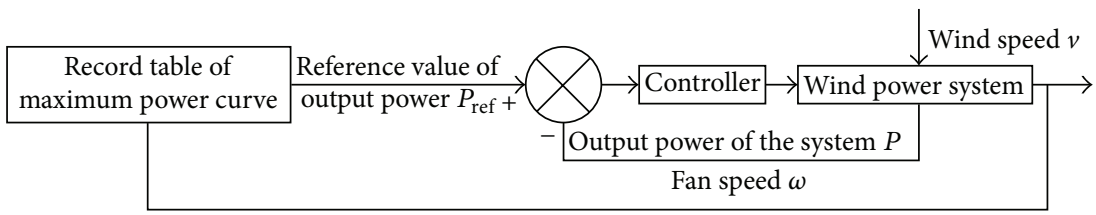

FIGURE 5: Block diagram of power curve control.

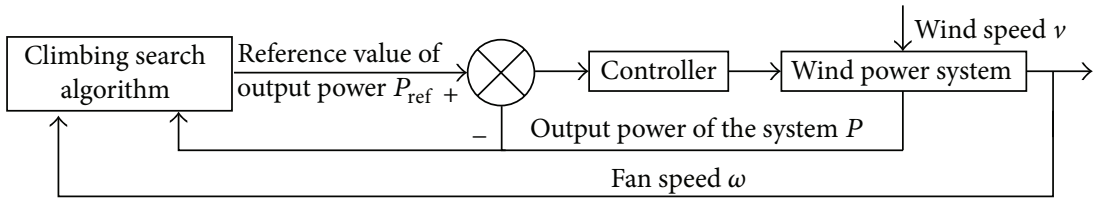

FIGURE 6: Block diagram of climbing mountain.

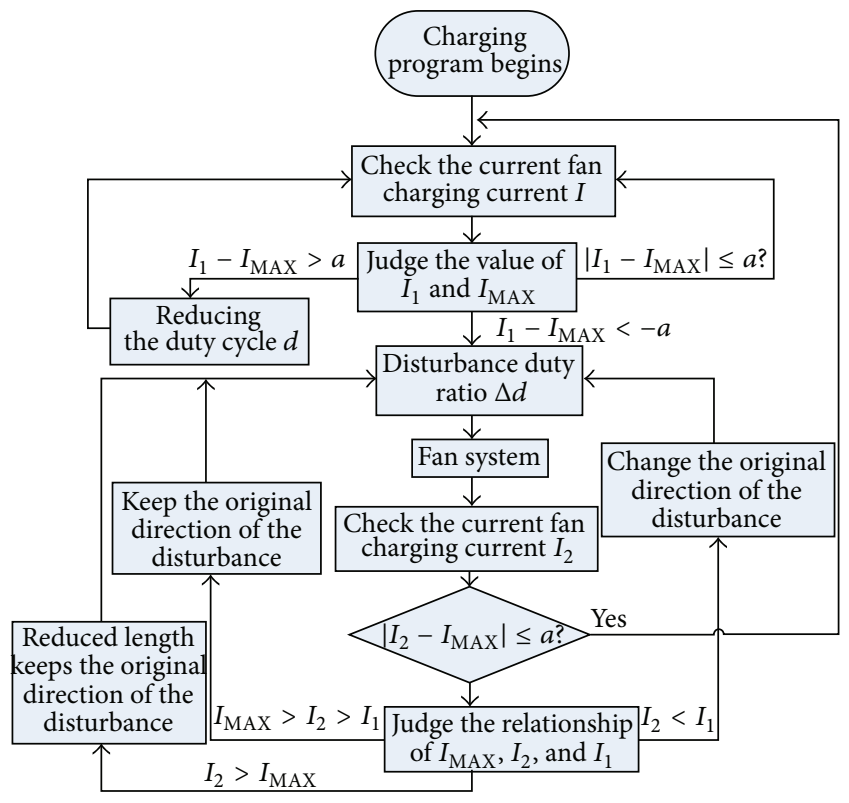

FIGURE 7: Flow chart of MPPT using climbing mountain method.

If $\left|I_{2}-I_{\max }\right|<\alpha$. If $I_{\max }>I_{2}>I_{1}$, increase the disturbance duty according to the original direction. If $I_{2}<I_{1}$, decrease the disturbance duty according to the opposite direction.

\section{Buck Converter Design}

Buck converter is a typical DC/DC device, which has been used widely in DC regulated power supply, photovoltaic

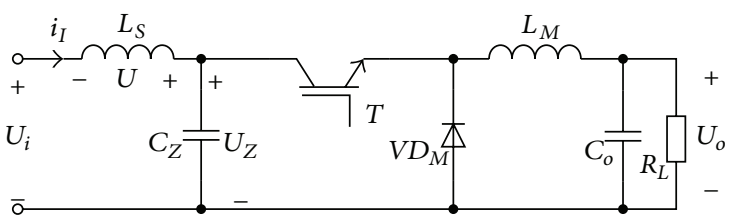

FIGURE 8: The conventional Buck converter topological structure.

system, DC motor regulated speed, LED illumination, and other electrical power and electronics systems [15-17].

In a wind generation system, the output voltage of the rectifier from the PMSG is usually higher than the battery voltage (DC bus voltage). For voltage reduction between the rectifier output and the DC bus, the Buck converter is used widely due to its simple structure, low cost, and easy control.

3.1. Conventional Buck Converter. The topology of a conventional nonisolated Buck converter is shown in Figure 8.

In a wind generation system, the converter has a long and wide wire connection from the forestage due to the height of the wind turbine. Thus there exists a great stray inductance $L_{s}$. When the switch is off, the input current $i_{I}$ passes through the inductance $L_{s}$, which leads to

$$
\begin{aligned}
& U_{i}=-L_{s} \frac{d i_{I}}{d t}+U_{z} \\
& i_{l}=C_{z} \frac{d U_{z}}{d t} .
\end{aligned}
$$




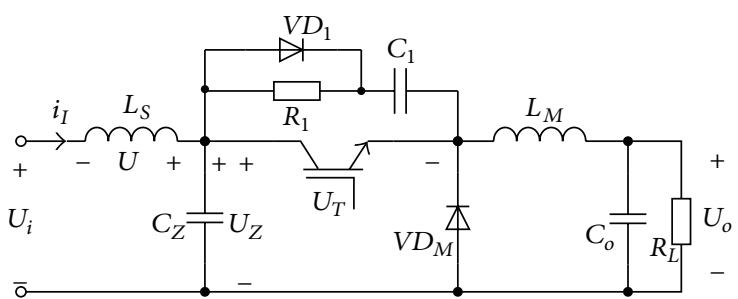

(a)

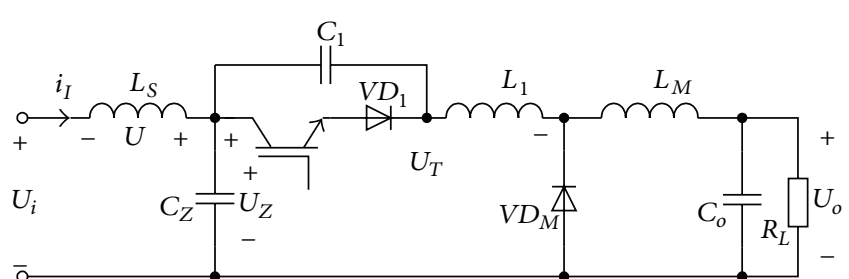

(b)

FIgURE 9: The improved Buck converter topological structure.

The solution of the above two equations is

$$
U_{z}=U_{i}+\sqrt{\frac{L_{s}}{C_{z}}} I_{I} \sin \left(\frac{t}{\sqrt{L_{s} C_{z}}}\right) .
$$

The maximum value of the equation above can be calculated as follows:

$$
U_{z \max }=U_{i}+\sqrt{\frac{L_{s}}{C_{z}}} I_{I} .
$$

With the presence of a stray inductance, a high amplitude voltage spike $U_{z \max }$ will be produced, if the converter does not include an absorption capacity. When the input current $i_{I}$ is higher, the value of $U_{z \max }$ is greater. Therefore, the use of an absorption capacitance $C_{z}$ is necessary. However the capacitance value $C_{z}$ should be selected carefully, especially in high frequency.

With a higher output power of the wind generation system, the electric wires are greater and longer, leading to the increase of the stray inductance. In high power applications, the change of current is significant when the power device works at high frequency, resulting in the huge voltage spike between the switch ends.

This phenomenon is common especially in high power Buck converter. The voltage spike at switch-off and the current spike at switch-on yield high electric stress. Sometimes, it can even break down the power device, such as MOSFET or IGBT. The switching loss can be significant. Thus the converter efficiency is usually between $60 \%$ and $80 \%$.

In order to overcome these shortages, the suppression of voltage or current spike and the improvement of the efficiency become the key issue in high power Buck converter design. An improved Buck converter topology is proposed in the following section.

3.2. Improved Buck Converter. The absorption circuit plays the crucial function for removing or decreasing the voltage spike in high power Buck converter. Two different absorption circuits, called RCD and LCD absorption, respectively, are presented in Figure 9.

In this paper, the resistance $R_{1}$, the capacitance $C_{1}$, and the diode $V D_{1}$ consist of the RCD absorption circuit in Figure 9 (a). The inductance $L_{1}$, the capacitance $C_{1}$, and the diode $V D_{1}$ consist of LCD absorption circuit in Figure 9(b).

In Figure 9(a), the RCD absorption circuit can eliminate the voltage spike when the power device is switched off. But the energy stored in capacitor is dissipated to resistance in the circuit. Thus the system efficiency is decreased.

In this topology, the relation between converter voltage and current can be expressed by

$$
\begin{aligned}
U_{i} & =-L_{s} \frac{d i_{I}}{d t}+U_{T}+L_{M} \frac{d i_{I}}{d t}+U_{o}, \\
i_{I} & =C_{1} \frac{d U_{T}}{d t} .
\end{aligned}
$$

The maximum value of the solution of the above two equations is

$$
U_{T \max }=U_{i}-U_{o}+\sqrt{\frac{L_{s}+L_{M}}{C_{1}} I_{I}^{2}+\left(U_{i}-U_{o}\right)^{2}} .
$$

The absorption capacity $C_{1}$ plays an important role in suppression of the voltage spike.

When the switch is on, $R_{1}, C_{1}$, and switch device $T$ build a discharge circuit. The stored energy in absorption capacity $C_{1}$ from the voltage spike is consumed by the resistance $R$. Considering the maximum discharge current of capacity $C_{1}$ as $I_{T \text { max }}$, discharge time as $\tau$, power loss in resistant as $P_{\text {loss }}$, and the switch frequency as $f$, the following expression can be obtained, ignoring the conduction voltage drop:

$$
\begin{aligned}
I_{T \max } & =\frac{U_{T \max }}{R_{1}}, \\
\tau & =2 R_{1} C_{1}, \\
P_{\text {loss }} & =\frac{1}{2} f C_{1} U_{T \max }^{2} .
\end{aligned}
$$

The values of $I_{T \max }$ should be smaller for security of the switch device. That means the resistance $R_{1}$ should be big enough. But if the value of $R_{1}$ is too big, it will affect the discharge time and thereby the efficiency. The $C_{1}$ and $R_{1}$ in the circuit should use the noninductive elements due to their good high frequency characteristic.

A LCD absorption circuit can also decrease the voltage spike in the Buck converter. The LCD topology is presented in Figure 10(b). The resistance is not used in this kind of circuit. Thus the loss energy is equal to zero in theory. This topology is also called zero-voltage switches (ZVS). Due to the resonance of the inductance $L$ and capacitance $C$, it can both accelerate the switch speed and reduce the voltage spike. Thus, the switching loss can be minimized. 


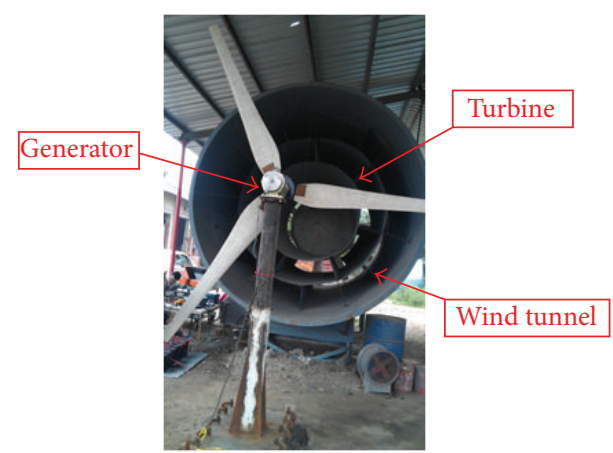

(a)

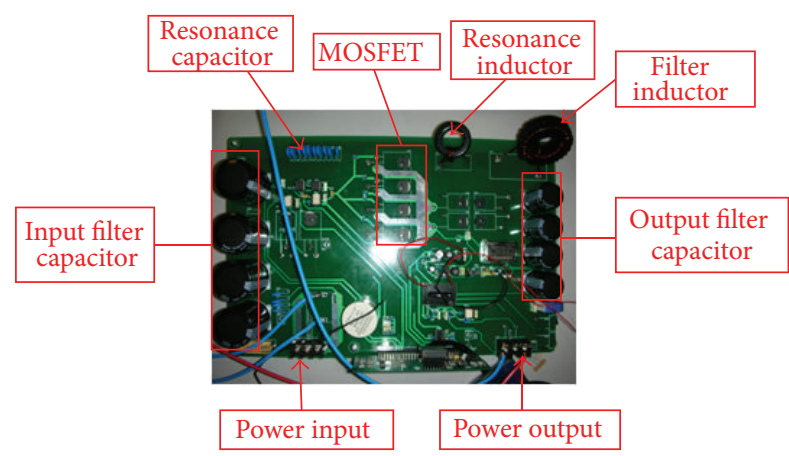

(b)

FIGURE 10: The actual wind generation system for experiment.

When LC resonance takes place, its resonant frequency can be calculated by

$$
f_{r}=\frac{1}{2 \pi \sqrt{L_{1} C_{1}}} .
$$

In order to reduce the influence on the PWM control, the resonant frequency of inductance $L_{1}$ and capacitance $C_{1}$ should be 4 to 10 times greater than switch frequency $f$. That is,

$$
f_{r}=N f
$$

where the value of $N$ should be between 4 and 10. The value of resonance inductance $L_{1}$ and capacitance $C_{1}$ can be calculated by

$$
\begin{aligned}
L_{1} & =\frac{Z_{r}}{2 \pi f_{r}}, \\
C_{1} & =\frac{1}{2 \pi f_{r} Z_{r}},
\end{aligned}
$$

where $Z_{r}$ is the resonant impedance. This impedance depends on voltage and current of LC resonance circuit.

In this paper, the topology of Buck converter with LCD absorption is adopted.

In high power converter applications, IGBTs are commonly used in the literature, whereas the MOSFETs are rarely adopted. Considering switch frequency and cost, the use of multi-MOSFETs in parallel is proposed in this paper for a $2 \mathrm{~kW}$ Buck converter. The converter uses four MOSFETs in parallel to increase the conduction current. Each MOSFET has $44 \mathrm{~A}$ conduction current at $20^{\circ} \mathrm{C}$ and $500 \mathrm{~V}$ withstand voltage.

\section{Experiment Result}

The experimental system consists of a $2 \mathrm{~kW}$ wind turbine and generator, with power converter, four batteries rated at $200 \mathrm{Ah}$ in parallel, and load. The test platform and the designed DC/DC Buck converter are presented in Figure 10. The experimental parameters are displayed in Tables 1, 2, 3, 4 , 5 and 6.
TABLE 1: Wind turbine parameter.

\begin{tabular}{lc}
\hline Number of blades & 3 \\
Blade radius & $1.7 \mathrm{~m}$ \\
Optimum ratio of tip speed & 6.7 \\
Maximum power coefficient & 0.42 \\
Nominal wind speed & $10 \mathrm{~m} / \mathrm{s}$ \\
Cut-in wind speed & $3 \mathrm{~m} / \mathrm{s}$ \\
Cut-off wind speed & $22 \mathrm{~m} / \mathrm{s}$ \\
\hline
\end{tabular}

TABLE 2: PMSG parameter.

\begin{tabular}{lc}
\hline Nominal power & $2 \mathrm{~kW}$ \\
Nominal rotor speed & $450 \mathrm{rpm}$ \\
Nominal current & $7 \mathrm{~A}$ \\
Line-to-line voltage & $190 \mathrm{~V}$ \\
Number of pole pairs & 4 \\
Winding resistance & $1.1 \mathrm{ohm}$ \\
Winding inductance & $14.1 \mathrm{mH}$ \\
\hline
\end{tabular}

TABLE 3: Rectifier parameter.

\begin{tabular}{lc}
\hline Full bridge & 3 \\
Conductive current & $35 \mathrm{~A}$ \\
Reverse breakdown voltage & $1600 \mathrm{~V}$ \\
Operation temperature & $-55 \sim 150^{\circ} \mathrm{C}$ \\
\hline
\end{tabular}

TABLE 4: DC bus parameter.

\begin{tabular}{lc}
\hline Capacitance & $2200 \mathrm{uF}$ \\
Maximum voltage & $500 \mathrm{~V}$ \\
Maximum current & $50 \mathrm{~A}$ \\
\hline
\end{tabular}

The experimental test results at the wind speed of $8 \mathrm{~m} / \mathrm{s}$ are shown in Figures 11 and 12. It can be concluded that the measured data is in agreement with the theory analysis in Figure 11.

From Figure 12, it can be seen that, with the designed converter topology, the minimum efficiency of the Buck 


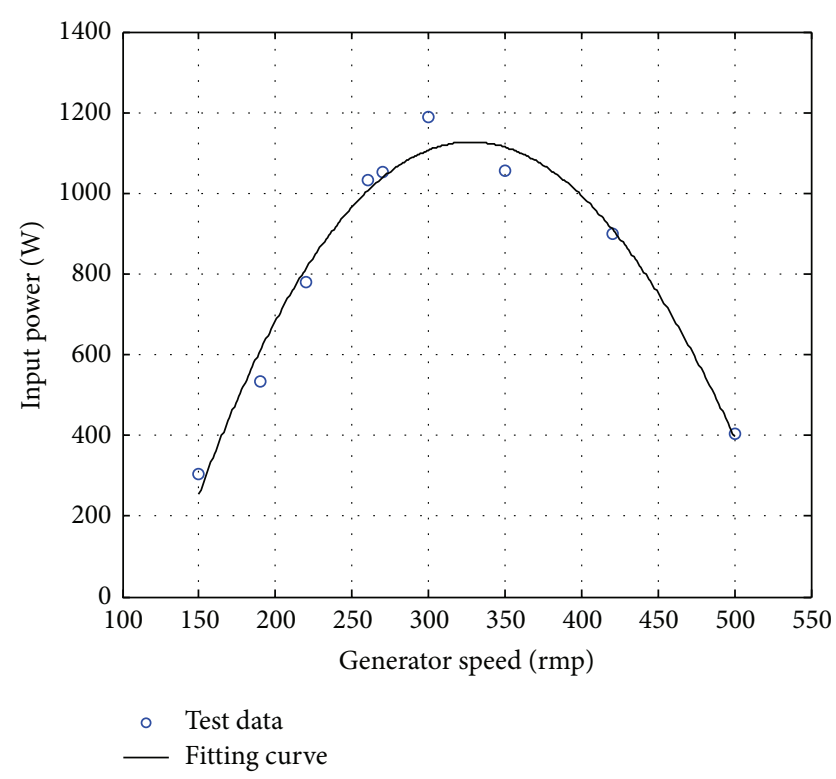

FIGURE 11: The input power of Buck converter versus generator speed at $8 \mathrm{~m} / \mathrm{s}$.

TABLE 5: Buck converter parameter.

\begin{tabular}{lc}
\hline Input filter capacitance & $470 \times 4 \mathrm{uF}$ \\
Switch device & IXYS44N50 \\
Resonance capacitance & $10 \mathrm{uF}$ \\
Resonance inductance & $1.2 \mathrm{uH}$ \\
Diode & DSEI60-06 \\
Output filter capacitance & $47 \times 4 \mathrm{uF}$ \\
Output filter inductance & $200 \mathrm{mH}$ \\
Switch frequency & $20 \mathrm{kHz}$ \\
\hline
\end{tabular}

TABLE 6: VRLA parameter.

\begin{tabular}{lc}
\hline Battery capacity & $200 \times 4 \mathrm{Ah}$ \\
Nominal voltage & $48 \mathrm{~V}$ \\
Maximum charge/discharge current & $56 \mathrm{~A}$ \\
Charge/discharge rate & $0.1 \mathrm{C}$ \\
\hline
\end{tabular}

converter is $86 \%$, and the maximum efficiency point can reach $96 \%$.

Figure 13 shows the experiment curve of input power for Buck converter versus generator power at $10 \mathrm{~m} / \mathrm{s}$ wind speed. The generator gives over $2 \mathrm{~kW}$ power output at $240 \mathrm{rpm}$. The parallel MOSFETs structure in the improved Buck converter can work without any problem under high power output level.

The experimental results show that the improved Buck converter has a good performance in the high power wind system. In addition, a comparison of the two absorption circuits, RCD and LCD, is also made. Figure 14 shows a $23 \mathrm{~A}$ charge current to VRLA battery for converter RCD and LCD tests.

Comparing Figures 15 and 16, the voltage spike is clearly more significant in RCD absorption circuit. Thus, the switching loss in RCD circuit is greater than in LCD circuit.

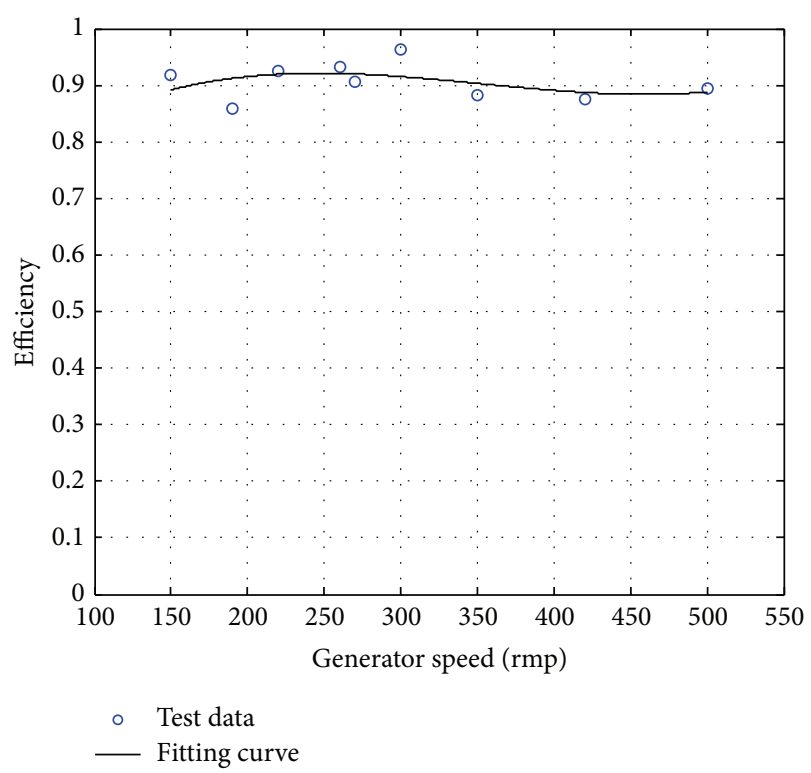

FIGURE 12: The efficiency of Buck converter versus generator speed.

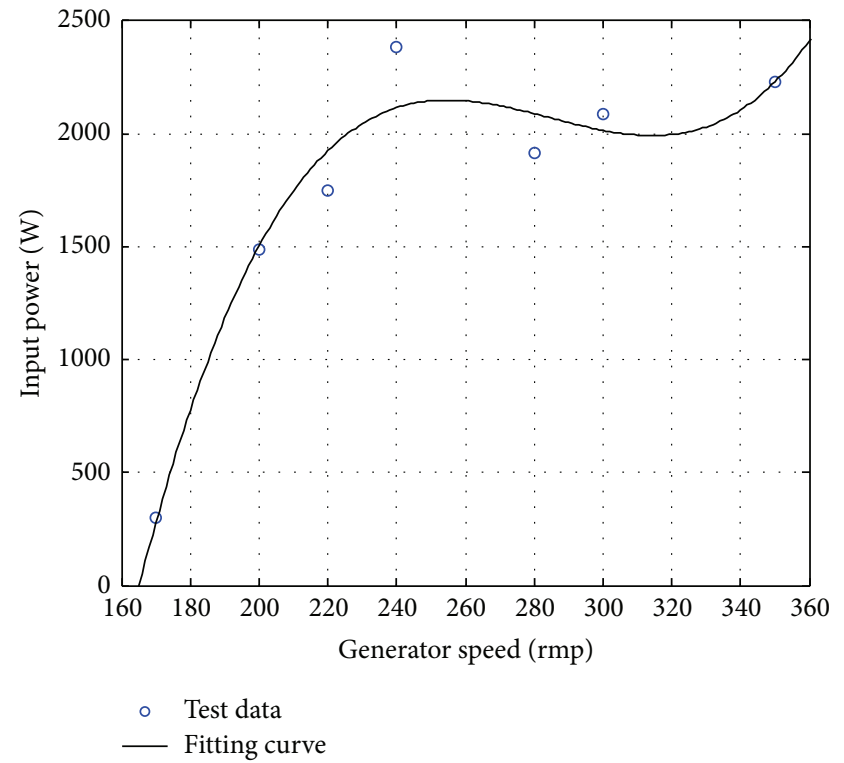

FIgURE 13: The input power of Buck converter versus generator speed at $10 \mathrm{~m} / \mathrm{s}$.

Moreover, owing to the consumptive resistance, the efficiency of this absorption circuit is very low. The experiment results show that the RCD circuit efficiency is only around $45 \sim 65 \%$.

\section{Conclusion}

In recent years, the cost of wind energy is close to the traditional thermal power generation. Furthermore, it is a clean energy without any pollution. The wind energy is a common energy in nature. In this paper, an off-grid wind generation system is presented and discussed. A high power efficiency converter is designed based on the DC/DC Buck 


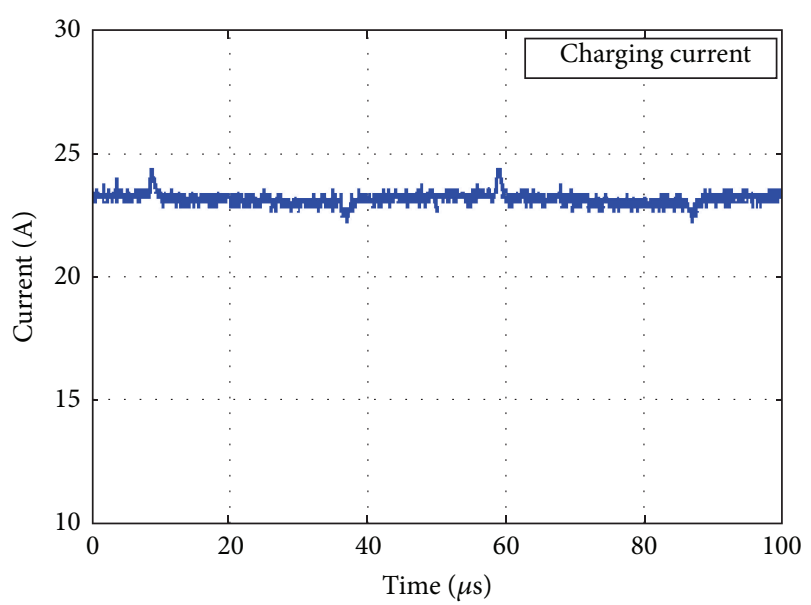

FIGURE 14: The charge current for VRLA battery.

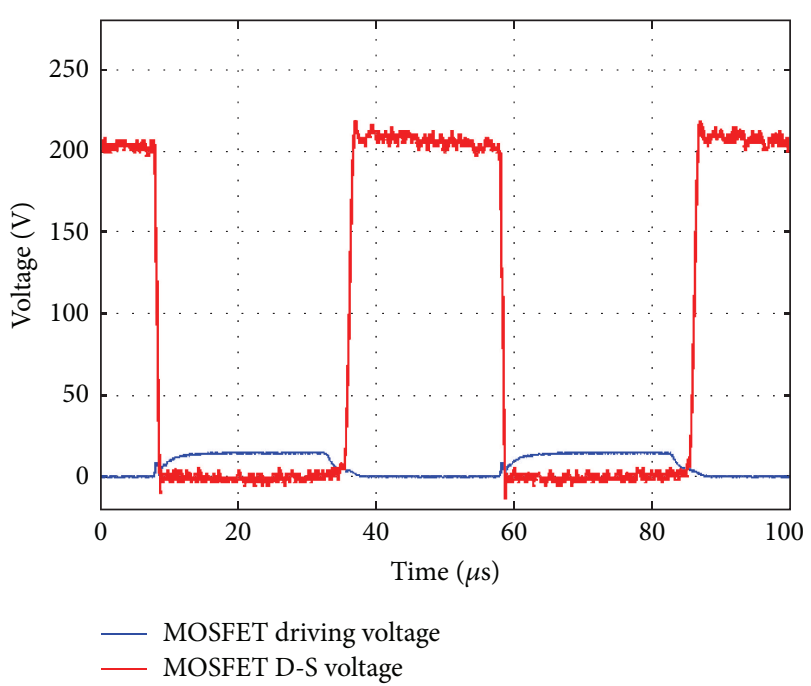

FIGURE 15: The Buck converter with LCD absorption circuit.

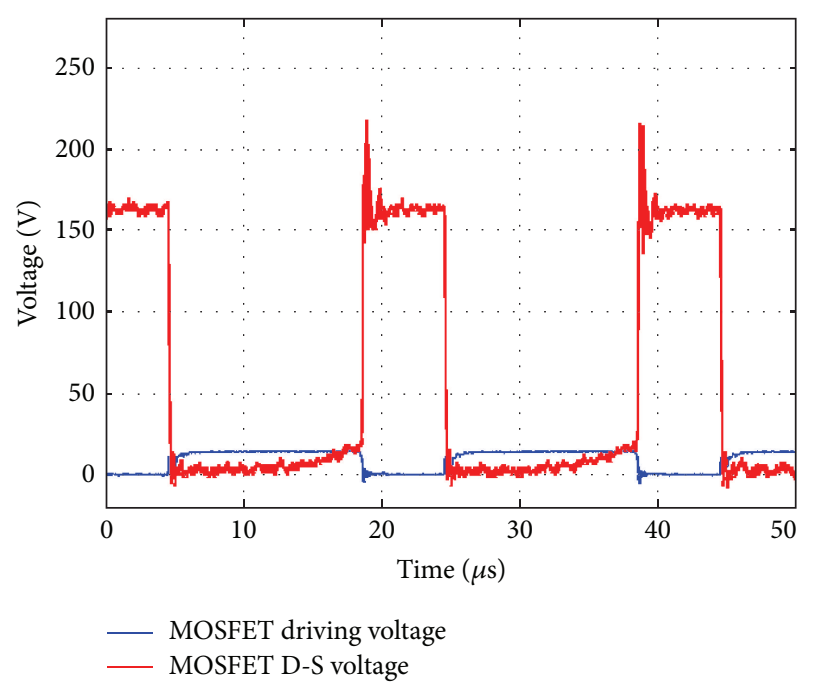

FIGURE 16: The Buck converter with RCD absorption circuit. converter topology. Considering the characteristic of wind generation, maximum power point tracking technology is preferred.

An improved efficient LCD combinational circuit in the Buck converter is proposed for a $2 \mathrm{~kW}$ off-grid wind generation system. In order to reduce the system cost, instead of IGBT device the paralleled multi-MOSFET structure is also used.

The experiments results show that the improved MOSFET based Buck converter with LCD absorption circuit can work without problem at $2 \mathrm{~kW}$ power output level. The maximum efficiency of the designed converter is up to $96 \%$. The proposed converter topology and control method provide a valid solution for wind turbine applications.

\section{Conflict of Interests}

The authors declare that there is no conflict of interests regarding the publication of this paper.

\section{References}

[1] N. Lior, "Energy resources and use: the present situation and possible paths to the future," Energy, vol. 33, no. 6, pp. 842-857, 2008.

[2] P. D. Lund, "Effects of energy policies on industry expansion in renewable energy," Renewable Energy, vol. 34, no. 1, pp. 53-64, 2009.

[3] P. A. Østergaard, "Reviewing optimisation criteria for energy systems analyses of renewable energy integration," Energy, vol. 34, no. 9, pp. 1236-1245, 2009.

[4] J. Wen, Y. Zheng, and F. Donghan, "A review on reliability assessment for wind power," Renewable and Sustainable Energy Reviews, vol. 13, no. 9, pp. 2485-2494, 2009.

[5] M. Hoogwijk, B. de Vries, and W. Turkenburg, "Assessment of the global and regional geographical, technical and economic potential of onshore wind energy," Energy Economics, vol. 26, no. 5, pp. 889-919, 2004.

[6] J. Wei and F. C. Lee, "Two novel soft-switched, high frequency, high-efficiency, non-isolated voltage regulators-the phaseshift buck converter and the matrix-transformer phase-buck converter," IEEE Transactions on Power Electronics, vol. 20, no. 2, pp. 292-299, 2005.

[7] J. Zhang, J.-S. Lai, R.-Y. Kim, and W. Yu, "High-power density design of a soft-switching high-power bidirectional dc-dc converter," IEEE Transactions on Power Electronics, vol. 22, no. 4, pp. 1145-1153, 2007.

[8] Y. C. Chuang and Y. L. Ke, "High efficiency battery charger with a buck zero-current-switching pulse-width-modulated converter," IET Power Electronics, vol. 1, no. 4, pp. 433-444, 2008.

[9] K.-Y. Lo, Y.-M. Chen, and Y.-R. Chang, "MPPT battery charger for stand-alone wind power system," IEEE Transactions on Power Electronics, vol. 26, no. 6, pp. 1631-1638, 2011.

[10] Y.-Y. Hong, S.-D. Lu, and C.-S. Chiou, "MPPT for PM wind generator using gradient approximation," Energy Conversion and Management, vol. 50, no. 1, pp. 82-89, 2009.

[11] S. Heier, Grid Integration of Wind Energy Conversion Systems, John Wiley \& Sons, Chicester, UK, 1998. 
[12] T. J. E. Miller, Brushless Permanent-Magnet and Reluctance Motor Drives, Oxford University Press, New York, NY, USA, 1989.

[13] K. A. Stol and M. J. Balas, "Periodic disturbance accommodating control for blade load mitigation in wind turbines," Journal of Solar Energy Engineering, vol. 125, no. 4, pp. 379-385, 2003.

[14] Q. Wang and L. Chang, "An intelligent maximum power extraction algorithm for inverter-based variable speed wind turbine systems," IEEE Transactions on Power Electronics, vol. 19, no. 5, pp. 1242-1249, 2004.

[15] V. Mummadi, "Fourth order buck converter for photovoltaic maximum power point tracking applications," in Proceedings of the IEEE International Conference on Sustainable Energy Technologies (ICSET '08), pp. 295-300, 2008.

[16] S. K. Mazumder, M. Tahir, and S. L. Kamisetty, "Wireless PWM control of a parallel DC-DC buck converter," IEEE Transactions on Power Electronics, vol. 20, no. 6, pp. 1280-1286, 2005.

[17] H. F. Bilgin, K. N. Köse, G. Zenginobuz et al., "A unity-powerfactor buck-type PWM rectifier for medium/high-power DC motor drive applications," IEEE Transactions on Industry Applications, vol. 38, no. 5, pp. 1412-1425, 2002. 

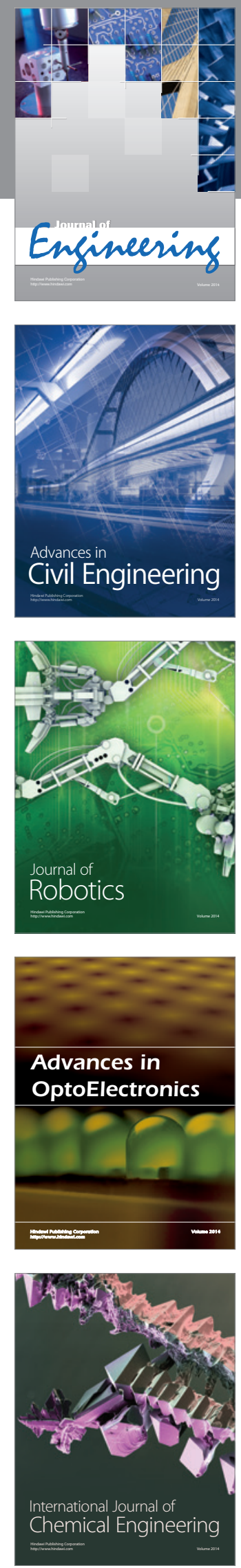

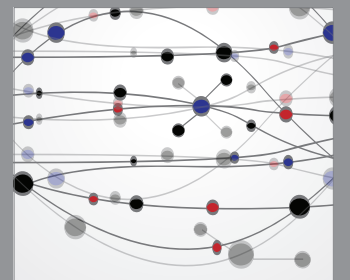

The Scientific World Journal
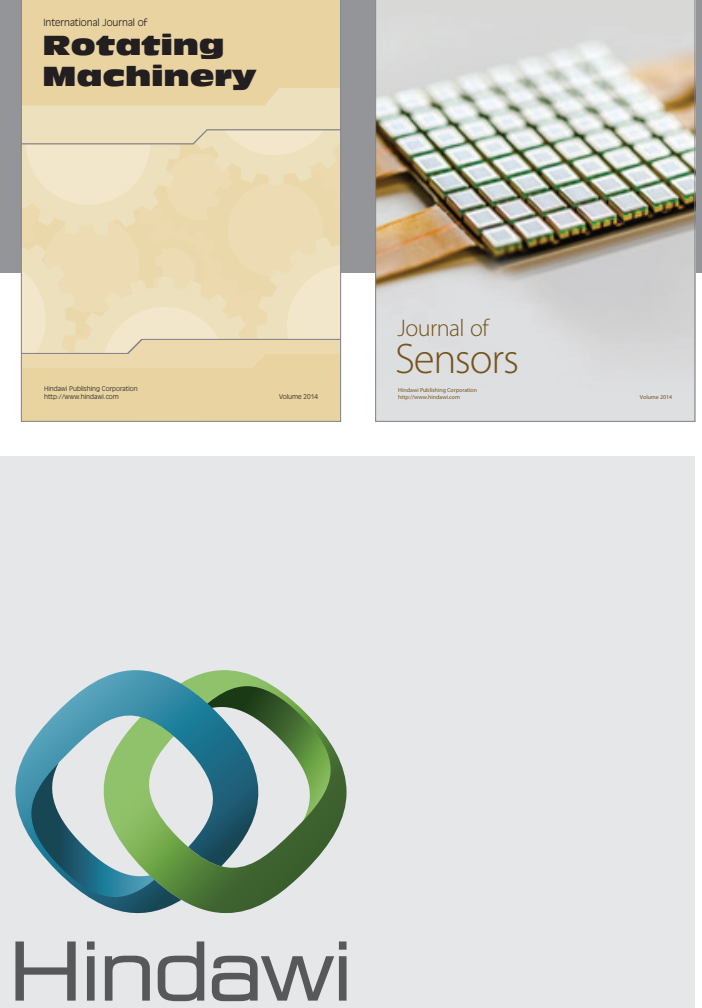

Submit your manuscripts at http://www.hindawi.com
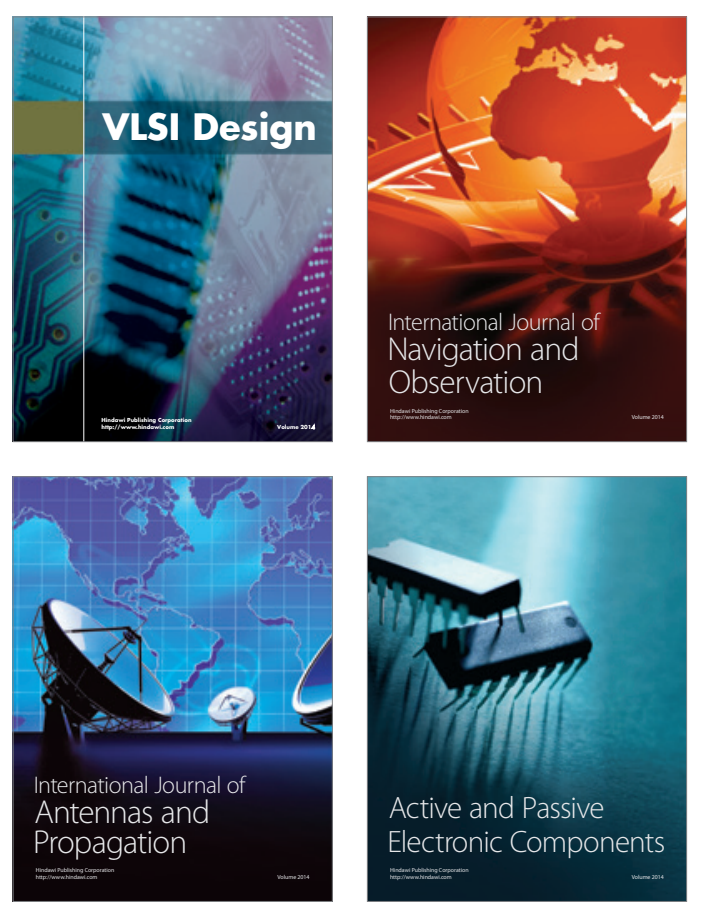
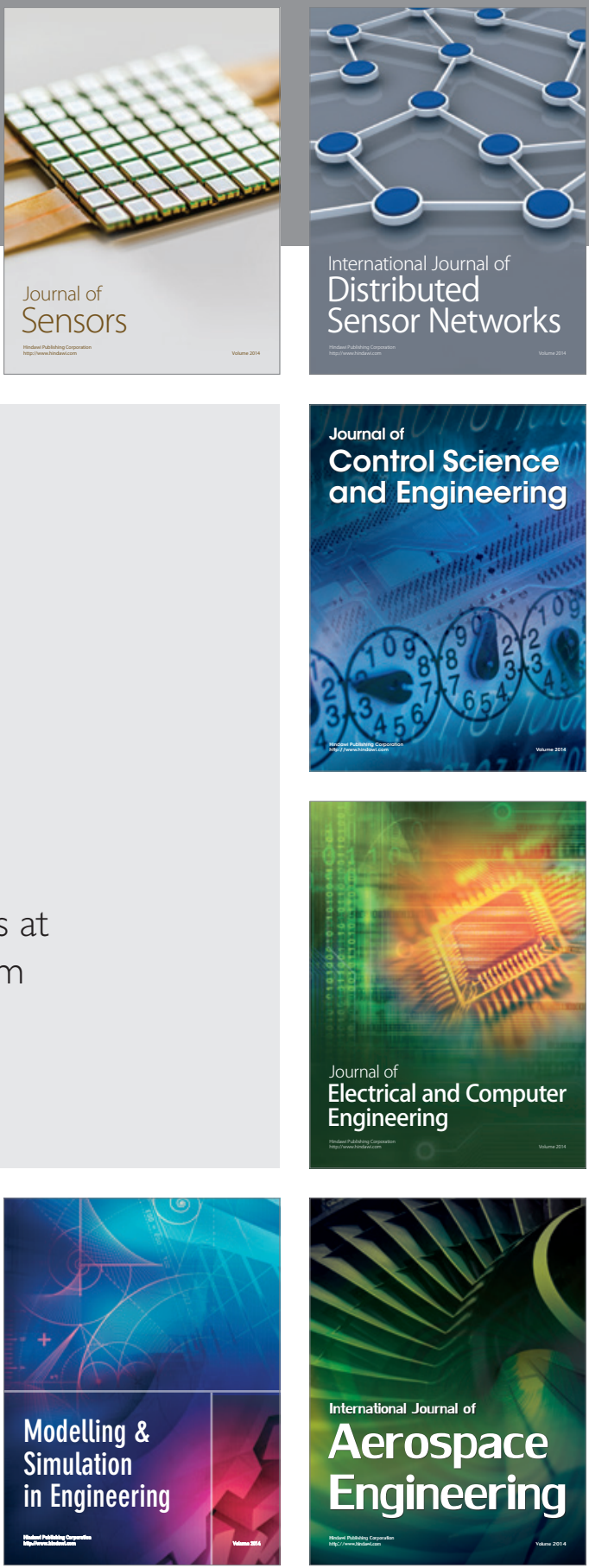

Journal of

Control Science

and Engineering
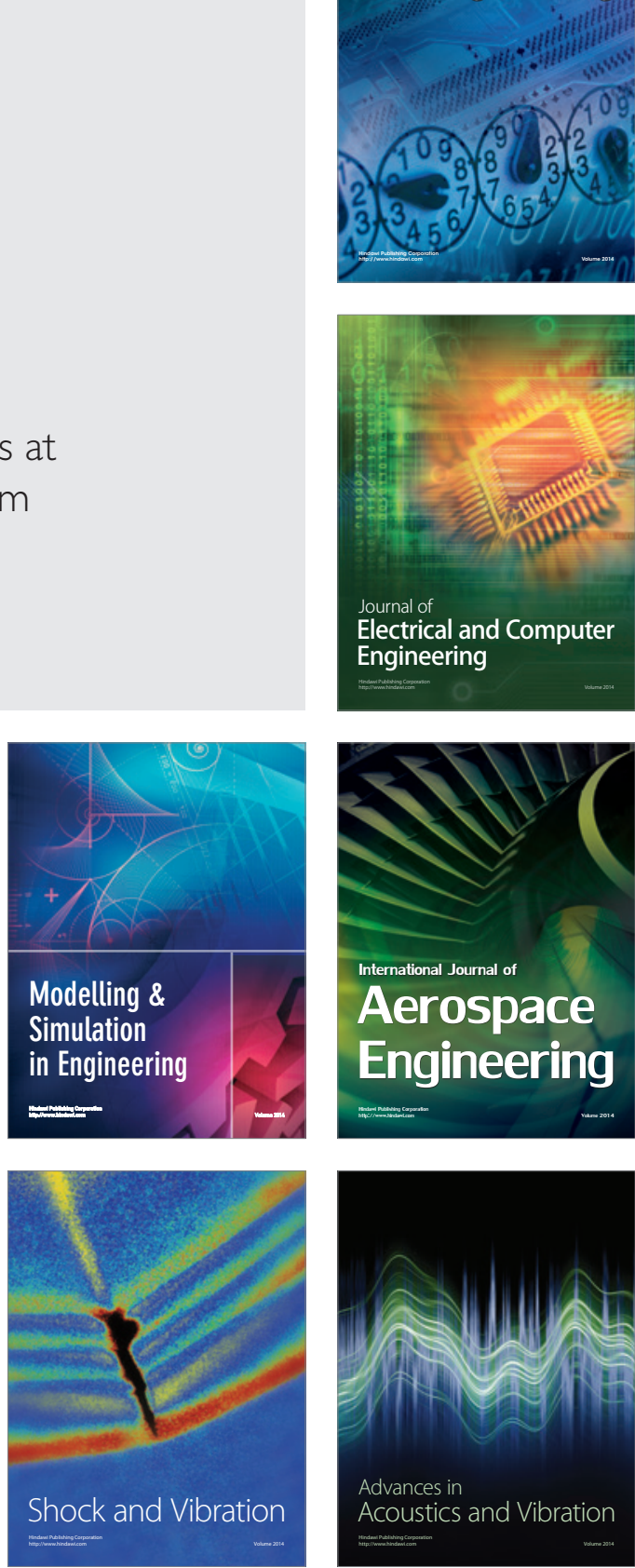